Palimpsesto Vol. 11, № 19 (Julio-diciembre, 2021): 54-75

Universidad de Santiago de Chile, ISSN 0718-5898

María Josefina Lamaisón

Universidad Nacional de La Plata

mjlamaison@hotmail.com.ar

\title{
Universidad y movimiento estudiantil frente a la cuestión nacional: una mirada desde Cristianismo y Revolución (1966- 1971)
}

\author{
University and Student Movement Facing the National Question: A \\ View from Cristianismo y Revolución (1966-1971)
}

\begin{abstract}
Resumen
Entre 1955-1976 en Argentina se produjo un ciclo de creciente conflictividad y movilización social. En ese contexto, emergieron procesos de radicalización política que convergieron con el origen de las organizaciones de la Nueva Izquierda, quienes proyectaron un extenso campo revisteril como forma de intervención ante los dilemas que caracterizaron la época de los sesenta. El presente artículo, recupera desde la perspectiva de la historia intelectual, la revista Cristianismo y Revolución, editada entre 19661971, por intelectuales católicos radicalizados, con el objetivo de analizar las discusiones que entabló este grupo editor sobre la universidad y el papel del movimiento estudiantil frente a la cuestión nacional, en el marco de oposición a la dictadura de la Revolución Argentina, la progresiva agitación social con acentuada participación de sectores universitarios, los cambios atravesados por el peronismo proscripto y la complejización del mundo católico desde el accionar de los movimientos tercermundistas.
\end{abstract}

Palabras claves: Universidad, Movimiento Estudiantil, Compromiso Intelectual, Cuestión Nacional, Católicos Radicalizados.

\begin{abstract}
Between 1955-1976 Argentina experienced a cycle of growing conflict and social mobilization. In that context, processes of political radicalization emerged that converged with the origin of the organizations of the New Left, who projected an extensive field as a form of intervention in the face of the dilemmas that characterized the time of the sixties. This article recovers from the perspective of intellectual history, the journal Cristianismo y Revolución, published between 1966-1971, by radicalized Catholic intellectuals, with the aim of analyzing the discussions that this editorial group engaged in about the university and the role of the student movement in the face of the national question, in the context of opposition to the dictatorship of the Argentine Revolution, the progressive social upheaval with the accentuated participation of university sectors, the changes crossed by the proscribed Peronism and the complexity of the Catholic world from the actions of the Third World movements.
\end{abstract}

Keywords: University, Student Movement, Intellectual Engagement, National Question, Radicalized Catholics. 


\section{Introducción}

Entre 1955-1976 la historia argentina vivenció un ciclo de creciente conflictividad y movilización social, que alcanzó tanto a integrantes del movimiento obrero como del estudiantil (Gordillo, 2003; Altamirano, 2001; Buchbinder, 2005). En ese marco, se suscitaron procesos de radicalización política, que convergieron tiempo después en diversos movimientos sociales, culturales y políticos que dieron origen a lo que podemos denominar como Nueva Izquierda argentina (Tortti, 2005; Terán, 2013). Las organizaciones que la compusieron se caracterizaron por poner en cuestión el orden imperante a partir de múltiples estrategias disruptivas, entre otras, huelgas y estallidos espontáneos desde las corrientes clasistas del movimiento obrero, iniciativas de renovación en los partidos políticos tradicionales, agitación y organización de la lucha universitaria estudiantil y surgimiento de organizaciones políticas revolucionarias que pregonaban la lucha armada.

En este contexto, las revistas político culturales editadas por diferentes grupos intelectuales, asociados a las universidades públicas y privadas, se convirtieron en canales de debate, divulgación y circulación de ideas respecto del proceso de modernización cultural, protesta social y malestar político que imperaba en Argentina durante esos años. La edición de revistas respondió a la necesidad de los intelectuales de izquierda de intervenir a través de sus palabras en la coyuntura política (Gilman, 2003). Rápidamente, lo que se denominaría la "cuestión nacional", esto es, la proscripción del movimiento peronista suscitó una revisión interna, así como un proceso de autoculpabilización de los intelectuales por su alejamiento histórico de las clases populares y del partido político al que las masas apoyaban con persistente entusiasmo. Los acalorados debates tomaron protagonismo en las múltiples páginas de revistas como Antropología 3er. Mundo, Los Libros, Envido y Cristianismo y Revolución. Revistas que expresaron, a su vez, los efectos de la creciente politización y partidización de la vida universitaria donde se entablaron tales discusiones (Barletta y Tortti, 2002).

En las páginas siguientes nos centraremos en el abordaje de Cristianismo y Revolución (en adelante $C y R$ ), editada entre 1966-1971, por intelectuales católicos radicalizados provenientes del integralismo, del nacionalismo y del humanismo cristiano. ${ }^{1}$ Cabe señalar que varias investigaciones previas abordaron la revista, entre estos estudios, destacamos el trabajo de Laura Lenci (2003) quien presenta una descripción inicial de la publicación, de los intelectuales que escribían en ella, así como de los principales tópicos que abordó la revista. Por otra parte, Daniela Slipak (2015) avanza en la reconstrucción del universo editorial montonero previo al golpe de Estado de 1976 y propone pensar a $C y R$ como una revista de identidad "proto-montonera"; no porque fuera órgano de Montoneros sino porque para la autora fue un antecedente simbólico que marcó los órganos de prensa que más tarde sostendría esta organización armada. La tesis doctoral

\footnotetext{
${ }^{1}$ El presente artículo forma parte de los debates entablados en seminarios de posgrado y en reuniones académicas del Proyecto I+D (T069) "Para una historia de los intelectuales argentinos y latinoamericanos del siglo XX. Un estudio de las revistas y publicaciones editadas por agrupamientos culturales, universitarios y políticos (1917-1990)" de la Universidad Nacional de La Plata (UNLP), dirigido por Adrián Celentano. La labor de investigación que permitió este escrito fue financiada por el programa de becas doctorales de la UNLP. Agradezco la lectura atenta y los comentarios de versiones preliminares a María Cristina Tortti, a Natalia Bustelo, a los evaluadores de Palimpsesto y a los demás autores de los artículos que compone este dossier. También a los investigadores del Centro de Documentación e Investigación de la Cultura de Izquierdas (CeDInCI), que desde el portal América Lee posibilitan el acceso a los distintos ejemplares de la revista Cristianismo y Revolución.
} 
de Esteban Campos (2016) avanza en el examen de las redes de sociabilidad que sostuvo este grupo intelectual y las escisiones internas que alejarían a $C y R$ de ser considerada una revista "montonera".

Tales estudios centralizan su análisis en el eje que relaciona violencia armada, política y religión católica durante los años sesenta, sin detenerse en los lazos que los intelectuales de $C y R$ establecieron con el movimiento estudiantil y los debates que suscitaron a través de las páginas de la revista sobre la universidad y la revolución. No obstante, registramos que Nicolas Dip (2016) en su tesis doctoral "Libros y alpargatas", reconstruye las tramas discursivas y organizativas que sustentaron el proceso de peronización de los universitarios de la Universidad de Buenos Aires (UBA). Para ello analiza los debates sobre la cuestión universitaria que sostuvieron Antropología 3er. Mundo y Envido, entrecruzando vínculos con $C y R$ al recuperar el protagonismo de los sectores estudiantiles cristianos en los debates acontecidos en la universidad porteña. En su investigación, revisa los comunicados emitidos por el Frente Estudiantil Nacional y la Federación Universitaria Argentina, que $C y R$ reprodujo al interior de sus páginas en 1970, en un intento de llamado a la unidad obrero-estudiantil.

El breve repaso por estos estudios resulta valioso para el conocimiento del agrupamiento intelectual que editó $C y R$ así como para el discernimiento de las redes de sociabilidad que posibilitaron la circulación de ideas y el vínculo con otras organizaciones católicas, laicas y/o armadas. Sin embargo, consideramos que a partir de las herramientas brindadas por la historia intelectual tales investigaciones pueden complejizarse. La pregunta que realiza esta perspectiva histórica sobre los debates intelectuales como instancias de construcción de sentido, habilita el análisis de $C y R$ sobre tópicos escasamente explorados como los debates entablados sobre la universidad y el papel del movimiento estudiantil en el marco de oposición a la dictadura de la Revolución Argentina, de una creciente agitación social con acentuado protagonismo de los sectores universitarios, de los cambios internos atravesados por el peronismo y la complejización del mundo católico desde el accionar de los movimientos tercermundistas.

El "giro material" operado en la historia intelectual durante los años noventa, dio impulso a los estudios sobre revistas y posibilitó que tuvieran un lugar cada vez más relevante. Este enfoque nos ofrece elementos renovados para impartir el estudio de publicaciones periódicas como soportes materiales de las intervenciones de los agrupamientos intelectuales en un contexto determinado (Chartier, 1996; Tarcus, 2007; Devés Valdéz, 2007; Altamirano, 2013). Partimos de comprender a las revistas culturales como las plataformas privilegiadas de los colectivos intelectuales para desplegar sus estrategias de disputa con otros grupos. Entendemos que los proyectos revisteriles expresan y producen al mismo tiempo a estos colectivos, es decir, las revistas los cohesiona y contribuye a forjar su identidad. A partir de estos "artefactos" los intelectuales se pronunciaron, pudieron ir más allá de sí, inscribiéndose en "una red de lectores y colaboradores, avisadores, suscriptores y distribuidores" (Tarcus, 2020, p. 23). De allí que, las revistas sean siempre por definición programáticas: su propósito es intervenir en los debates culturales del presente (Sarlo, 1992). Razón por la que, priorizaremos en este artículo, un abordaje de análisis que enfatiza las relaciones entre lo "material" y lo "contextual", entre el contexto de producción y circulación sin reducir el sistema de comunicación al mero texto.

Asimismo, conceptualizamos a quienes protagonizaron el proyecto revisteril de $C y R$ como intelectuales. Con esta categoría teórica no pretendemos acotar su accionar a la condición socio-profesional que los nuclea, sino también aludir a la relación que mantuvieron con la esfera pública participando de los debates cívicos y sociales, a través de la propagación de la cultura impresa, que interpeló a un público que fue más allá de la élite de letrados (Altamirano, 2013). 
María Josefina Lamaisón

Consideramos que la recuperación de estas fuentes documentales posibilita visualizar cómo las revistas y su vocación de intervenir en la esfera pública respecto a diversos tópicos, las vincula estrechamente a cuestiones políticas, convirtiéndose su análisis en un mirador privilegiado para comprender los cambios políticos e ideológicos que operaron en una determinada coyuntura (Sarlo, 1992; Beigel, 2003; Pita González, 2014). Indagar los ejemplares de $C y R$ nos permite comprender cómo se expresó el modo de intervención que este agrupamiento realizó en el campo cultural argentino en la época de los sesenta (Gilman, 2003).

El presente artículo busca interrogar la experiencia de $C y R$ en el marco de la "cuestión nacional" en tanto construyó representaciones sobre el movimiento estudiantil y su rol en el proceso eminentemente contestatario. El escrito intenta responder dos interrogantes centrales: ¿Qué discursos sobre los estudiantes y la universidad aparecieron en $C y R$ entre 1966-1971? ¿Qué debates establecieron los intelectuales de $C y R$ en relación a la lucha revolucionaria, el compromiso intelectual y el legado de la Reforma Universitaria de 1918? Las indagaciones realizadas nos permiten mostrar que, el lugar destacado que otorgó $C y R$ en sus discusiones a la vía armada, como camino hacia la revolución triunfante, no obturó los debates sobre el compromiso que el estudiantado católico universitario debía tener -junto al "pueblo" y al movimiento obrero- para la liberación nacional; así como la urgente revisión de los postulados de la Reforma de 1918 y del quehacer de la universidad frente a la proscripción del peronismo y la creciente persecución por parte de los militares argentinos.

\section{El proceso de radicalización política frente a la "cuestión nacional"}

El período iniciado con el golpe de Estado de 1955, encabezado por el Gral. Eduardo Lonardi, autoproclamado Revolución Libertadora, estuvo marcado por la inestabilidad del sistema político dada la proscripción del peronismo, por la creciente ilegitimidad de poder del Estado y por diversas crisis económicas. En este contexto, creció la conflictividad social, escalaron los índices de protesta entre los trabajadores y emergió cierto malestar en las capas intelectuales de las clases medias (sector que inicialmente apoyó el golpe pero que luego lo rechazó por su tono represivo y antipopular). Simultáneamente se desplegó un intenso proceso de modernización cultural y radicalización política, que se aceleró a partir del golpe de Estado de 1966, encabezado por el Gral. Juan Carlos Onganía y autodenominado Revolución Argentina. Entre 1969 y fines de 1970 estalló la rebelión popular, conformándose movimientos sociales de oposición al régimen que ensayaron nuevos repertorios de confrontación. Finalmente, en el trienio que va de 1971 a 1973 se produjo el pasaje a la acción política de los nacientes movimientos (Gordillo, 2003).

La imagen recurrente para mirar esos años es la de un estado de contestación generalizada por parte de la sociedad. Ahora bien, Claudia Gilman (2003) nos propone pensar los años sesenta y setenta como "época", ya que durante ese período convergieron "coyunturas políticas, mandatos intelectuales, programas estéticos y expectativas sociales que modificaron los parámetros institucionales y los modos de leer y producir discursos" (p. 4). Afloraron nociones que, al calor de la Revolución Cubana, la descolonización africana, la guerra de Vietnam, la rebelión antirracista en los Estados Unidos y los brotes de rebeldía juvenil, constituyeron la percepción de que el mundo estaba por cambiar y que los intelectuales tenían un papel fundamental en esa transformación. 
Esa revisión del papel político fue acompañada por un proceso de "autoculpabilización" de los intelectuales argentinos debido a su histórico alejamiento de los sectores populares, en particular de los afines al peronismo (Terán, 2013). Las bases integrantes de partidos de izquierda, que se consideraban representantes de la clase obrera, como el Comunista y el Socialista, no podían observar impasibles el hecho de que la mayoría no sólo había votado a Perón, sino que se había vuelto peronista (Altamirano, 2001). La "cuestión nacional" o "peronista" incitó arduos debates en el ámbito universitario: se volvió objeto de investigación y disputa entre sectores que revisitaron la definición del peronismo, el papel político revolucionario que debía ejercer la academia, los valores de la Reforma Universitaria de 1918 y la idea de la universidad como "isla democrática". 2

Por otra parte, emergieron movimientos que contribuyeron al desarrollo de la protesta social y la radicalización política, que incluyó desde el estallido espontáneo y la revuelta cultural hasta al accionar guerrillero. Englobamos los nacientes movimientos bajo el concepto de Nueva Izquierda. Con él aludimos no sólo al conjunto de las organizaciones armadas, sino al movimiento social, político y cultural contestatario que incluyó militantes marxistas que rompieron con los partidos de la izquierda ortodoxa, activistas obreros con prácticas anticapitalistas, nacionalistas revolucionarios y antiimperialistas $\mathrm{y}$, grupos cristianos posconciliares. A pesar de su heterogeneidad, estos grupos que provenían del peronismo, de la izquierda, del nacionalismo y de la Teología de la Liberación, resultaban convergentes en sus discursos de oposición a la dictadura y al "sistema", entrelazando tendencias de corte revolucionario en el que ocupó centralidad el "compromiso" de los intelectuales, que simpatizados por la "causa del pueblo", avanzarían hacia formas de participación política directa (Tortti, 2005, p. 6).

El "aggiornamento" de la Iglesia argentina aceleró la radicalización de los jóvenes católicos, que rechazaron la vieja antinomia marxismo-catolicismo, aglutinando un movimiento anticapitalista que miraba con anhelos la Revolución triunfante en Cuba (Altamirano, 2001). ${ }^{3}$ Esta novedosa intersección entre el catolicismo y la izquierda marxista se expresó en diversas organizaciones, fundamentalmente en aquellas afines al llamado Peronismo Revolucionario (Bozza, 2014). Allí encontramos las pertenecientes a comunidades cristianas de base que, identificadas con los cambios posconciliares, intentaron traducir los evangelios en el compromiso por la emancipación de los pobres y excluidos de la sociedad. Curas, seminaristas y laicos, como el colectivo de intelectuales que editó $C y R$, realizaban labores comunitarias en zonas territorialmente ancladas como los campos marginalizados, las villas miserias y los barrios fabriles profesando un cristianismo revolucionario.

\footnotetext{
${ }^{2}$ Entre los postulados que sostuvo el movimiento estudiantil que encabezó la Reforma Universitaria de 1918, se destacaron la libertad de cátedra, el co-gobierno, la autonomía, la importancia de la investigación y la extensión como formas de acercarse al "pueblo" (Bustelo, 2018). La idea de la Universidad como "isla democrática", refiere a la pretendida extraterrioriarilidad de esta institución de los avatares de la política nacional, una especie de "refugio externo" con independencia del Estado y un status autónomo de los partidos políticos. Esta idea moldeó la identidad universitaria estudiantil reformista. Hasta los años sesenta los bloques universitarios argentinos no fueron la reproducción de partidos políticos, lo que no implica que sus integrantes no estuvieran politizados (Sigal, 1991).

${ }^{3}$ Desde los sucesos cubanos, los jóvenes de la Nueva Izquierda, más radical que la tradicional, comenzaron a concebir el futuro en términos de una ruptura general encarnada en la revolución. El juvenilismo encontró un nuevo florecimiento, convirtiéndose en objeto de exaltación y de militancia (Altamirano, 2001, 2011). Progresivamente Cuba devino puente entre izquierda, nacionalismo y peronismo creando en él un ala izquierda (Sigal, 1991).
} 


\section{Intelectuales católicos comprometidos: la revista Cristianismo y Revolución}

Como señalamos, partiremos de comprender el proyecto editorial de $C y R$ como parte de la Nueva Izquierda y a quienes escribían en la revista bajo el modelo del intelectual católico revolucionario. Esta figura, inspirada en la Revolución Cubana, expresa la conjunción de las ideas de "compromiso" y "revolución". La tarea intelectual contiene simultáneamente una dimensión descriptiva y prescriptiva. Describe el contexto y propone que es lo que debería hacerse en él, asumiendo un compromiso colectivo con los grupos de la sociedad (Altamirano, 2013). Los intelectuales debían realizar un acto de humanidad frente al imperialismo, proclamando la liberación de los "pueblos oprimidos" del Tercer Mundo. Dicha conjunción se imbricó en Argentina, con el proceso de autoculpabilización de los intelectuales de izquierda quienes habían vivido su condición como privilegio y separación respecto del "pueblo", especialmente por su ubicación política que les impidió comprender el peronismo. La asunción del compromiso incluía una forma de "rescate" y/o valorización de aquello que no había sido entendido.

En consonancia con las revisiones de la época, la Iglesia Católica transformó su discurso pastoral. A partir del papado de Juan XXIII, que proclamó las encíclicas Mater et Magistra (del 15 de mayo de 1961) y Pacem in terris (del 11 de abril de 1963), se estrecharon contactos con los países tercermundistas, celebrando en 1968 la conferencia general del episcopado latinoamericano en Medellín. Allí nació "la convicción de la necesidad de un nuevo orden dentro de amplios sectores de la dirigencia y la intelectualidad católicas" (Gilman, 2003, p. 7). Había llegado la hora del compromiso. ${ }^{4}$

Compromiso y militancia política se convirtieron en elementos distintivos de las jóvenes generaciones que compartían la idea de que el cambio debía constituirse sobre la vía revolucionaria y que los adversarios eran las fuerzas del Estado. Las organizaciones de estudiantes laicos y católicos se fortalecieron y el orden universitario fue criticado por ser funcional a los sectores dominantes. La progresiva politización brindó nuevos tintes políticos al movimiento estudiantil, fortaleciéndose el peso de los grupos de raigambre católica en las casas de estudios del interior del país, donde desde mediados de los años sesenta, el reformismo cedió posiciones frente a las agrupaciones católicas y nacionalistas en Córdoba, Santa Fe y el Nordeste (Buchbinder, 2005). ${ }^{5}$

En este contexto, proliferó la publicación de revistas académicas culturales como Antropología 3er. Mundo, Los Libros, Envido y CyR. ${ }^{6}$ A través del extenso circuito de edición,

${ }^{4}$ Clérigos tercermundistas se convirtieron en referentes máximos de laicos, religiosos, grupos de estudio, obreros y estudiantes afines a la opción revolucionaria (Touris, 2007).

${ }^{5}$ En tales provincias emergieron ateneos universitarios católicos que promovieron los cambios provocados en la Iglesia. Muchos jóvenes hacían simultáneamente a sus estudios tareas de asistencia social en zonas marginales (Bozza, 2014). Asimismo, la militancia social y política resultaba favorecida por la existencia de ámbitos de sociabilidad estudiantil como los comedores o residencias universitarias. En Córdoba se fortaleció el llamado Movimiento Integralista que reunía al estudiantado católico radicalizado alejado de los sectores más conservadores.

${ }^{6}$ La revista Antropología 3er. Mundo se editó desde Buenos Aires bajo la dirección de Guillermo Gutiérrez. Contó con 12 números editados entre noviembre de 1968 y marzo de 1973. Entre sus colaboradores y redactores se destacaron: Cristina Merediz, Ricardo Álvarez Capdevila, Egle Zomero, Susana Pitkin y Roberto Carri. Vinculada a las Cátedras Nacionales de la Facultad de Filosofía y Letras de la Universidad de Buenos Aires, la publicación entabló debates en torno al rol de los intelectuales, la nacionalización del estudiantado y la cuestión universitaria. La revista Los Libros se editó en Buenos Aires entre julio de 1969 y enero-febrero de 1976. Con una periodicidad 
favorecieron la circulación de nociones concernientes al orden social instaurando debates sobre los dilemas de la época. Produjeron discursos y prácticas apoyadas en la posesión de un saber con la intencionalidad de intervenir en la esfera pública social, ideológica y política (Sigal, 1991). Dichas revistas no pueden ser comprendidas desde su mera singularidad. Es necesario inscribirlas en el campo de fuerzas en el que batallaron por su reconocimiento, en el que establecieron alianzas y/o rivalidades con otras revistas contemporáneas (Tarcus, 2020). Hecha la aclaración adentrémonos en el abordaje especifico de $C y R$.

Como anticipamos, se fundó en 1966 en Buenos Aires, fue editada por intelectuales provenientes del integralismo, del nacionalismo y del humanismo cristiano, tuvo una tirada que iba de 2.000 a 5.000 ejemplares, con una duración total de 30 números. Desde el primer ejemplar de septiembre de 1966 hasta el $\mathrm{N}^{\circ} 22$ de enero de 1970, fue dirigida por el periodista católico Juan García Elorrio; un ex-seminarista de la diócesis de San Isidro, que experimentó una trayectoria de vertiginosa radicalización en la que confluyeron su raíz cristiana posconciliar y su acercamiento al Peronismo Revolucionario. ${ }^{7}$ García Elorrio murió de forma dudosa el 26 de enero de 1970 al ser atropellado por un vehículo que aparentemente se quedó sin frenos, mientras caminaba por la esquina de Bulnes y Las Heras. Sus allegados tuvieron la convicción de que fue asesinado. Desde ese momento su compañera Casiana Ahumada asumió la dirección, hasta que la publicación fue clausurada en 1971 por la dictadura militar del Gral. Alejandro Agustín Lanusse. ${ }^{8} \mathrm{La}$ revista se financió casi exclusivamente con los aportes monetarios que hacía Ahumada. ${ }^{9}$

$C y R$ funcionó como canal de difusión y toque de reunión de periodistas, sacerdotes, teólogos, sociólogos y militantes católicos, que venían radicalizando sus posiciones bajo el influjo de la Revolución Cubana, el Concilio Vaticano II (1962-1965) y la encíclica Populorum

mensual lanzó 44 números en total, siendo finalmente clausurada por la dictadura militar en mayo de 1976. Contó con diversos directores a lo largo de su publicación: Héctor Schmucler (del n ${ }^{\circ} 1$ al 28), Ricardo Piglia (del n ${ }^{\circ} 23$ al 39), Carlos Altamirano (del n॰23 al 43), Beatriz Sarlo (del n²5 al 43), Germán L. García (del n²5 al 28), Miriam Chorne (del $n^{\circ} 25$ al 28) y Osvaldo Bonano (del n 43 al 44). Entre sus colaboradores se encontraban: Santiago Funes, Horacio Ciafardini, Oscar Terán, Eliseo Verón, Guillermo Schavelzon, Cristina López Meyer, Isabel Carballo, Marcelo Díaz, Manuel Amigo y Jorge Brega. La revista Envido, fue dirigida por Arturo Armada desde Buenos Aires, entre julio de 1970 y noviembre de 1973. Editó un total de 10 números, con una impronta libre, autónoma y juvenil. Entre el consejo de redacción se destacaron: Domingo Bresci, José Pablo Feinmman, Jorge Luis Bernetti, Manuel Fernández López, Carlos Gil, Horacio González, Santiago González y Bruno Roura.

${ }^{7}$ García Elorrio nació en 1938 en una familia de clase media-alta que poseía vínculos con la Iglesia Católica. En 1959 ingresó al seminario de San Isidro para conformarse como sacerdote, pero abandonó dos años más tarde, inconforme con la orientación de los cursos. Fue secretario municipal de Marcos Paz por la Unión Vecinal de Vicente Solano Lima. En 1965 creó el Centro de Estudios Diálogos donde se dictaban cursos que animaban el debate teológico inspirados en el catolicismo renovador. En este espacio conoció a otros intelectuales como Ahumada, Gil Sola y Sabino Navarro, intelectuales que serían fundamentales para las redes políticas y culturales que facilitaron la edición y circulación de $C y R$. Participó de la agrupación Acción Revolucionaria Peronista liderada por J.W. Cooke. En 1967 dirigió la revista Che Compañero y el Comando Camilo Torres (Slipak, 2015; Campos, 2016).

${ }^{8}$ La cuestión cubana instaló el tema del "peligro comunista". El Ejército argentino se reorganizó alrededor del concepto de guerra "antirrevolucionaria" o "antisubversiva" e incorporó la idea de enemigo "interno". Los sectores de la Nueva Izquierda fueron perseguidos y varias revistas político-universitarias pagaron el costo de la censura.

${ }^{9}$ Ahumada nació en una familia de clase media en Córdoba. Su padre y abuelo eran reconocidos médicos en la provincia de Catamarca. Realizó sus estudios en colegios católicos, ingresó a la UBA a estudiar filosofía, carrera que dejaría luego de cuatro años. Participó del Comando Camilo Torres donde afianzó su vínculo con García Elorrio. En diciembre de 1971 fue arrestada luego de que la policía confiscara el último número de $C y R$. Al salir de la cárcel sostuvo lazos con el Bloque de Prensa Peronista y finalmente se exilió en 1973. 
María Josefina Lamaisón

Progressio (1967). Entre sus colaboradores se encontraban: Jorge Luis Bernetti (secretario de redacción), Ernesto Herrera, Luis García Guevara, Mario Vicente Tarico y Sofía Galíndez (equipo de redacción), Luis Agustín Acuña (asesor) y Oscar Pereira Dantas (diagramación). ${ }^{10}$ También aparecieron autores con secciones fijas: José Ricardo Eliaschev (con política internacional), Jorge Gil Solá (con peronismo revolucionario), Miguel Mascialino (con apuntes de Miguel Mascialino) y Gerardo Duejo (con columna de economía). ${ }^{11}$

En su tapa se autoproclama bimensual, pero apareció de forma irregular. Se editaron 30 números en cinco años, contando con una distribución que podríamos llamar "artesanal", puesto que sus colaboradores las repartían kiosco por kiosco o las llevaban en sus viajes. De igual manera circuló entre facultades y actividades de grupos ligados al catolicismo renovador. Los contenidos dan cuenta de un trayecto que va desde la teología a la política hasta el apoyo a la lucha armada. El formato atendía problemas nacionales, del mundo del trabajo, como los de América Latina y del Tercer Mundo. Inicialmente se dirigió a los sectores cristianos interpelados por la renovación posconciliar, pero rápidamente ese universo se amplió: al exponer las reflexiones teológicas sobre la problemática de la liberación y las protestas obrero-estudiantiles contra el gobierno militar, el público imaginado incluyó sectores no necesariamente identificados con el cristianismo liberacionista pero que deseaban transformar la realidad argentina $\mathrm{y}$ tercermundista.

Desde 1968 registramos una apelación a los sectores que terminaron conformando el Peronismo Revolucionario. Ello se advierte en la incorporación de la simbología peronista como puede observarse en el título de la tapa del N¹0 "Che, Perón, Octubre", que incluía la nota editorial titulada "Octubre" y "un mensaje del General Perón”, hasta la imagen de tapa del $\mathrm{N}^{\circ} 28$ de abril de 1971, donde aparecen insignias que refuerzan el apoyo de los intelectuales de $C y R$ a las organizaciones armadas revolucionarias:

\footnotetext{
${ }^{10}$ Bernetti inició su militancia en los sesenta en la Juventud Estudiantil Católica (JEC). Luego se acercó a la izquierda peronista a través de su participación en la Acción Revolucionaria Peronista (ARP), militó en la Democracia Cristiana y fue integrante de la Juventud Argentina para la Emancipación Nacional (JAEN). A comienzos de la década del setenta cofundó el Bloque Peronista de Prensa, que era parte de la Juventud de Trabajadores Peronistas.

${ }^{11}$ El periodista José "Pepe" Ricardo Eliaschev participó en 1964 de la revista Todo. Trabajó entre 1965-1969 en las revistas Gente, Confirmado y Análisis. Tras dos años en Roma, de regreso a la Argentina en 1971, participó del lanzamiento de la revista Nuevo Hombre y se acercó al peronismo entre 1972 a 1973. Fue redactor de la revista El Descamisado en 1973. Miguel Masciliano era un ex-sacerdote y había tenido actuación en los gremios combativos. Para los años de $C y R$ había dejado el sacerdocio y era director del Centro de Estudios Teilhard de Chardin, que mantenía vínculos con el Comando Camilo Torres del que formaba parte Jorge Gil Solá, Ahumada y García Elorrio. Por su parte, Eduardo Jorge Duejo, publicaba su columna en $C y R$ bajo el seudónimo "Gerardo".
} 
María Josefina Lamaisón

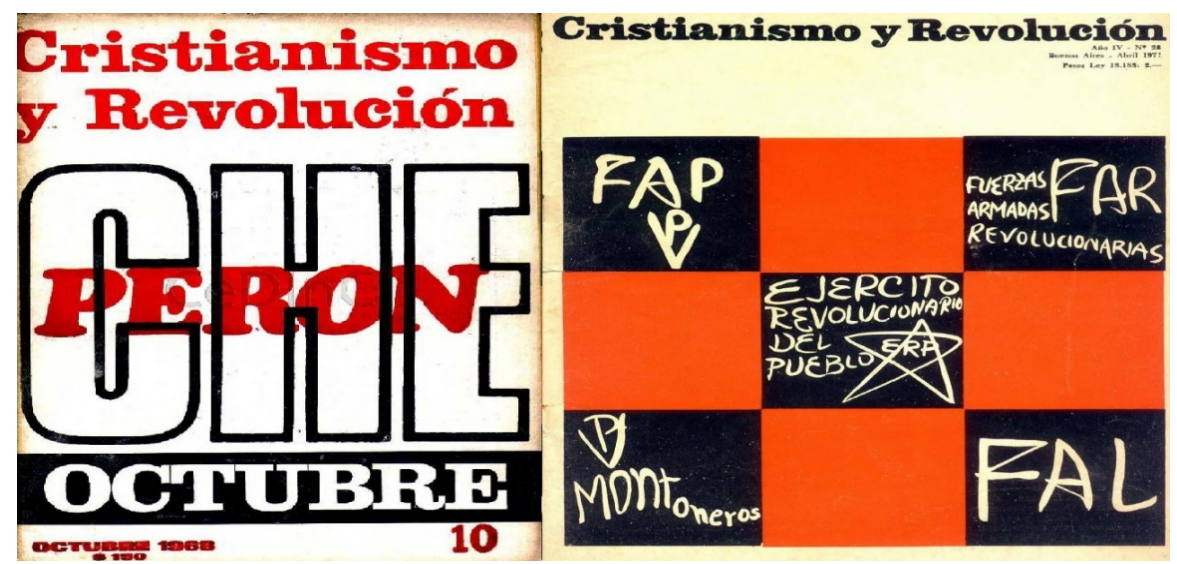

Ilustración 1. $C y R \mathrm{~N}^{\circ} 10$, octubre 1968, pág.1 y $C y R \mathrm{~N}^{\circ} 10$, abril 1971, pág.1

Otra de las conexiones con el peronismo de izquierda fue el apoyo a la experiencia de la Confederación General del Trabajo de los Argentinos (C.G.T.A.), cuyo proceso de auge y caída fue seguido en las páginas de $C y R$. Asimismo, abundaron notas y reportajes a referentes de los sindicatos combativos como Raimundo Ongaro, Juan Carlos Loureiro, Dante Oberlín, Benito Romano, Jorge Di Pasquale y Agustín Tosco. El interés por el sindicalismo combativo puede observarse en la atención que la revista prestó a los conflictos gremiales y en la oposición al sindicalismo "participacionista" de la Confederación General del Trabajo (C.G.T.) (Lenci, 2003). ${ }^{12}$

Como destacamos, desde sus inicios el joven grupo de intelectuales que reunió $C y R$ se nucleó por su acercamiento a la figura del sacerdote Carlos Francisco Sergio Mugica Echagüe, más conocido como "Padre Mugica". En paralelo al trabajo de edición, algunos miembros de $C y R$ crearon en 1967 el Comando Camilo Torres, una incipiente guerrilla urbana que se organizó en células compartimentadas según el modelo de la revolución argelina. ${ }^{13}$ Sus integrantes promediaban los 20 años de edad, entre los que se destacaron: García Elorrio, Ahumada, Fernando Abal Medina, Norma Arrostito, Emilio Maza, Carlos Gustavo Ramus y Mario Firmenich.

${ }^{12}$ En marzo de 1968 se creó la CGTA bajo el secretariado de Raimundo Ongaro (del gremio gráfico), con un proyecto de renovación sindical opositor a la dirigencia "burocratizada" de la CGT dirigida por Augusto Vandor (del gremio metalúrgico). La nueva central levantó las banderas del antiimperialismo contra los militares de la Revolución Argentina y compartió estas críticas con organizaciones del Peronismo Revolucionario. Entre los gremios que la compusieron se encontraban: Luz y Fuerza de Córdoba, la Unión Ferroviaria, Unión del Personal Civil de la Nación, Telefónicos, La Fraternidad y los Trabajadores del Estado. La central obrera estrechó vínculos con el movimiento estudiantil y con grupos tercermundistas, entre ellos, los afines a $C y R$. Hacia junio de 1969 los sindicatos que la integraban fueron intervenidos y varios de sus dirigentes encarcelados.

${ }^{13}$ Este grupo apareció en público el 1 de mayo de 1967, cuando irrumpió en la Catedral de Buenos Aires la misa del cardenal Antonio Caggiano para distribuir y leer volantes que reivindicaban la lucha revolucionaria, la libertad sindical y criticaban al gobierno militar. El episodio culminó con la detención y encarcelamiento de varios de sus integrantes, entre ellos, García Elorrio. Para mediados de ese año los "Camilos" sumaron nuevos militantes, algunos provenientes de la Juventud de Estudiantes Católicos de Buenos Aires, del Movimiento Universitario Cristo Obrero de Córdoba y de la Juventud Obrera Católica. Entre las tareas realizadas por el Comando se registran volanteadas, la distribución de $C y R$, la planificación de pequeñas acciones armadas y el dictado de charlas donde aunaban peronismo y revolución. Los Camilos se vincularon en su accionar con el comando Revolucionario Universitario y en 1968 pasaron a denominarse Comandos Peronistas de Liberación (Slipak, 2015; Campos, 2016). 
Algunos investigadores interpretan al Comando Camilo Torres como uno de los orígenes que permitió la formación de la organización armada Montoneros (Lenci, 2003) y avanzan en definir al Comando y a $C y R$ como identidades "proto-montoneras" (Slipak, 2015). Aunque es cierto que varios de los intelectuales de estos grupos luego serian destacados militantes de Montoneros, coincidimos con Campos (2016) cuando señala como simplificador concebirlos como "agrupaciones protomontoneras", puesto que, como adelantamos, si bien varios de sus miembros se vincularon efectivamente con Montoneros, otros migraron al Peronismo de Base y otros "Camilos" dejaron de militar orgánicamente. ${ }^{14}$

A estos espacios de sociabilidad debemos sumar los lazos que $C y R$ articuló con otros grupos de reflexión como el Centro de Estudios Teilhard de Chardin, dirigido por Miguel Mascialino y Pedro Geltman (curas que habían abandonado los hábitos); que en 1969 pasó a denominarse Centro de Estudios Camilo Torres. También destacamos el vínculo con otras revistas del Peronismo Revolucionario: Che Compañero, Con Todo y Antropología 3er. Mundo. ${ }^{15}$ Además registramos en $C y R$ la edición de notas de la revista chilena Punto Final, de la agencia cubana Prensa Latina, de la revista Marcha de Montevideo y de la revista Tricontinental de La Habana y la rivalidad con la revista Los Libros en la lectura que ambos grupos intelectuales hicieron en 1969 de los sucesos conocidos como el "Cordobazo".

\section{Compromiso, universidad y movimiento estudiantil: ¿Reforma o Revolución?}

Como indicamos en los apartados anteriores, a pesar de su propia lógica y autonomía, la vida universitaria argentina fue sometida a los avatares de la política nacional (Sigal, 1991). El golpe de Estado de 1966 y la consiguiente intervención de las casas de estudios clausuraron el periodo de renovación abierto en septiembre de 1955. A los conflictos internos originados por la orientación curricular, pedagógica y científica, o en relación a las funciones de la universidad, se sumaron las disputas políticas. La comunidad científica se fragmentó: crecieron las corrientes integralistas -de signo católico- y las de naciente neoizquierda, que rivalizaron con los sectores reformistas. Los nacientes agrupamientos estudiantiles insistían en mutar a la universidad en agente de transformación social y criticaban los debates exclusivamente "académicos". Como

\footnotetext{
${ }^{14}$ Varios fundadores de Montoneros provenían de grupos nacionalistas católicos, muchos habían militado en la agrupación nacionalista de derecha Tacuara, pero luego de la expansión del MSTM se acercaron a sectores desposeídos fundamentalmente por la influencia del sacerdote Mugica y los escritos de García Elorrio (Gordillo; 2003: 365). Abal Medina, Arrostito, Ramus y Firmenich, conocieron a García Elorrio por su relación con Mugica, cuando el primero actuaba como asesor de la Juventud Estudiantil Católica (JEC) en el Colegio Nacional Buenos Aires (Touris, 2007: 15). En 1968 estos militantes se separan del Comando Camilo Torres por sus desacuerdos con García Elorrio y tiempo después fundan Montoneros. La ruptura fue bautizada como "la rebelión de los enanos" (Slipak, 2015; Campos, 2016).

${ }^{15}$ La revista Che Compañero fue dirigida por García Elorrio desde Buenos Aires. Se editaron 4 números entre enero y agosto de 1968. La publicación surge por el acercamiento de su director al peronismo combativo. Las notas aparecen mayormente sin firma y se publicaron discursos de Perón, Eva Duarte y el "Che" Guevara; se incluyeron solicitadas y llamados de los Comandos Peronistas de Liberación, de la Juventud Revolucionaria Peronista, del Frente Revolucionario Peronista, de la Juventud Peronista, de la Agrupación 17 de octubre (Tucumán) y del Comando Camilo Torres. Entre sus colaboradores se destacaron: Hernán Benítez, Eduardo Galeano, Luis Cerruti Costa, Miguel Mascialino. La revista Con Todo fue dirigida desde Buenos Aires por Bernardo Alberte. Se editó entre 1968-1969 y fue declarada públicamente como órgano de prensa del Peronismo Revolucionario. Entre sus colaboradores se encontraban: Gustavo Rearte, Alicia Eguren, Gil Solá, García Elorrio, Ahumada y Mascialino.
} 
adelantamos, estos discursos impactaron en aquella vieja concepción que entendía a la universidad como "isla democrática".

Las organizaciones de la Nueva Izquierda no fueron ajenas a estas discusiones, debatieron la función social que debía tener la universidad y algunas reafirmaron que no habría reforma universitaria sin una verdadera revolución social. En esta trama revisionista, los intelectuales de $C y R$ intervinieron en la esfera pública, construyendo posicionamientos desde la revista sobre los dilemas políticos, sociales e ideológicos que operaron en la época de los sesenta. En lo que sigue, examinaremos los números publicados desde los aportes de la historia intelectual, con el objetivo de indagar cuáles fueron los debates que entabló este grupo editor en torno al papel de la universidad en la lucha por la liberación, su pretendida exterioridad o imagen de "isla democrática", el legado de la Reforma de 1918 y la participación del estudiantado en los procesos revolucionarios.

De los 30 números de $C y R$ registramos que sólo aparecen menciones al movimiento estudiantil en 13 ejemplares. Una de las primeras evocaciones la encontramos en el $\mathrm{N}^{\circ} 2 / 3$, de octubre-noviembre de 1966, donde se publicó un mensaje escrito por el sacerdote colombiano Camilo Torres. ${ }^{16} \mathrm{El}$ mensaje constituyó un llamado a los jóvenes estudiantes a comprometerse con los campesinos y trabajadores del "pueblo" cubano que habían iniciado el camino hacia la revolución. Allí se definió a los estudiantes como un grupo privilegiado puesto que, en cualquier país subdesarrollado, eran los pobres quienes sostenían a costos muy altos a los egresados de colegios y universidades. Asimismo, caracterizaban a los estudiantes universitarios con un doble privilegio: el poder de ascender en la escala social mientras avanzaban en los grados académicos y el poder de manifestar su rebeldía sin que esto impidiera tal ascenso.

Para Torres - y podríamos inferir para los intelectuales de $C y R$ que deciden transcribir el mensaje- ésta última ventaja posibilitó que los estudiantes fueran un elemento decisivo en la revolución. Sin embargo, advertían que la labor estudiantil sólo había sido decisiva y eficaz en la fase agitacional, pero no en la fase organizativa ni en la lucha directa, donde su papel había sido secundario y casi insignificante. Entendían que, hasta el momento, la contribución del estudiantado en la lucha por la transformación social resultaba transitoria y superficial, producto de la falta de compromiso en la lucha económica, familiar y personal y de que el inconformismo tendía a ser personal o puramente intelectual, lo que explicaba que al finalizar sus estudios pasaran de ser "rebeldes estudiantes a profesionales burgueses" $\left(C y R \mathrm{~N}^{\circ} 2-3,1966, \mathrm{p} .19\right)$. De allí, la invitación del cura guerrillero a involucrarse de lleno en la contienda de la liberación.

Los lectores de la revista tendrán que esperar dos años para que la cuestión universitaria vuelva a ser objeto de discusión. En efecto, encontramos en 1968, en la sección América Luchando relatos que contrastan con la mirada anterior, al subrayar la participación estudiantil en insurrecciones populares acontecidas ese mismo año. Bajo el título "La protesta en boca de los fusiles" se presenta el diálogo imaginario entre Rocael y César, un guerrillero y un estudiante, que conversaban sobre la incorporación de estudiantes a las guerrillas campesinas en Cuba. El mismo ejemplar de la revista transcribe una declaración del Movimiento Universitario de Acción Popular (MUAP) que enaltece el compromiso de los estudiantes colombianos en la lucha universitaria y con la sociedad en general. La organización estudiantil simpatizaba con el ideario político de Camilo Torres y celebraba la crisis histórica de los valores profesionales individualistas clasistas que acontecía en la universidad colombiana.

16 Torres nació en Bogotá en 1929 y sería conocido como el "primer cura guerrillero". 
Advertimos en la declaración un punto clave: el MUAP afirmaba que el pensamiento revolucionario brotaba entre los estudiantes y enfatizaba la necesidad de asumir un rol "concientizador". Aquí identificamos una doble operatoria por parte de los intelectuales de $C y R$ : al reproducir el comunicado del MUAP, por un lado, daban cuenta del proceso de concientización que atravesaba el movimiento estudiantil colombiano, llamando a enlazar frentes entre las acciones universitarias y las acciones de los sectores populares y, por otro, transcribían el documento para visualizar similitudes con el proceso agitacional que protagonizaban los estudiantes y las universidades tanto en Argentina, como en Cuba y en Colombia.

En los sucesivos números de la revista apreciamos que el grupo editor reitera la operatoria. Nuevamente en la sección América Luchando se incluyen experiencias de jóvenes universitarios, esta vez, las del movimiento estudiantil cubano. En ocasión de la conmemoración del decimoquinto aniversario del ataque al Cuartel Moncada, $C y R$ editó una solicitada de los estudiantes de Santa Clara. La nota titulada "Cuba: Ofensiva Revolucionaria. A 15 años del 26 de julio" destacaba la participación activa de todo el estudiantado -secundario, preuniversitario, universitario, tecnológico y futuros maestros- en el proceso de profundización ideológica. La solicitada enumeraba cambios realizados contra la educación escolástica como la utilización de medios auxiliares de enseñanza, la consulta a múltiples textos y autores, la concurrencia a bibliotecas, la desaparición del uso exclusivo de notas de clase y la participación junto a sectores obreros y campesinos en el propio seno de las actividades productivas.

También retomaba como bandera los idearios de Julio Antonio Mella y de Ernesto "Che" Guevara. ${ }^{17}$ Como ejemplo de esta exaltación hallamos que la revista transcribió las palabras emitidas por Guevara, en 1959, cuando recibió el Doctorado Honoris Causa de la Facultad de Pedagogía de la Universidad Central de Las Villas: "Las universidades deben abrir sus puertas al pueblo, pintarse de negro, de mulato, de obrero, de campesino o quedarse sin puertas y el pueblo las romperá, y pintará una universidad con los colores que le parezca" $\left(C y R \mathrm{~N}^{\circ} 9,1968\right.$, p. 41).

Por otra parte, observamos que en el transcurrir de las ediciones adquirió centralidad aquel discurso que pregonaba abandonar el "interior" de los recintos universitarios y "salir" al encuentro con los sectores populares. Para los intelectuales de $C y R$ la intervención directa -en los lugares de trabajo- implicaba una forma de estudio que generaba la construcción de conocimiento genuino sobre la realidad. En tal sentido, publicaron un informe emitido por la Agrupación de Estudios Sociales de la Universidad Católica de Córdoba que recuperaba un viaje realizado a la Provincia de Tucumán, con el objetivo de confeccionar un estudio que fuera más allá del análisis textual y estadístico, "un análisis desde el contacto con los hombres" $\left(C y R \mathrm{~N}^{\circ} 10,1968\right.$, p. 8). ${ }^{18}$

\footnotetext{
${ }^{17}$ Mella fue cofundador del Partido Comunista de Cuba, de la Federación Estudiantil Universitaria y de la Universidad Popular José Martí. Rápidamente paso de líder estudiantil a líder nacional. $C y R$ resaltó el vínculo personal que entabló con el sacerdote Varela con quien compartía la influencia del marxismo revolucionario y del pensamiento de José Martí. Guevara era graduado de la carrera de Medicina por la Universidad de Buenos Aires. Durante sus estudios había realizado viajes en motocicleta al norte de Argentina, visitando las regiones más empobrecidas del país. Luego emprendió rumbo por Latinoamérica donde conoció a dirigentes del Partido Comunista y a los líderes exiliados del Movimiento 26 de julio, quienes determinarían su visión revolucionaria. En 1957, Fidel Castro le daría el título de "comandante". Al igual que Mella, pasaría de estudiante a líder nacional al volcarse de lleno al accionar de las guerrillas cubanas.

${ }^{18}$ El estudio se realizó en dos fases: una incluía la realización de entrevistas a personas e instituciones que cumplían un papel protagónico como la Federación Obrera Tucumana de la Industria Azucarera y la Unión Cañeros Independientes de Tucumán y, otra fase de trabajo en zonas como San Pablo, Lules, San Ramón y Bella Vista donde vivían los obreros. El informe reflejaba, según los redactores, una situación de subdesarrollo. Contenía información referida a la estructura social tucumana y de tipo sociológico como las costumbres populares, el nivel
} 
Consideramos que, al editar el informe con los resultados que arrojó esta labor, la revista buscó fortalecer lazos entre los sectores universitarios y los obrero-campesinos. Allí aparece la cuestión del "compromiso" intelectual: los universitarios debían comprometerse con la lucha de los sectores populares en su propio terreno, salir del recinto universitario, conocer las condiciones de explotación y hacer investigaciones que produjeran conocimiento para la transformación social.

Luego de tres números, notamos que los debates sobre las formas de acceso a la universidad y sobre la construcción de conocimiento científico vuelven a ser objeto de discusión. En abril de 1969 se publicó el documento "Fidel Castro explica la revolución universitaria". Éste transcribía un discurso brindado en las escalinatas de la Universidad de La Habana donde se destacó la falta de contradicciones de los estudiantes que participaron del proceso revolucionario. Situación que intuimos -aparece en las voces de quienes escriben la revista- como un mérito político importante, ya que, la composición del estudiantado era heterogénea y la mayoría provenía de sectores burgueses.

Para reforzar la imagen de unidad entre universitarios, obreros y campesinos, percibimos en el documento la incorporación de relatos que dan cuenta de la participación de estudiantes en frentes para el desarrollo del país y de la creación de aulas universitarias en los centros de trabajo, donde se pretendía poco a poco, la desintegración de las estructuras físicas de la universidad, que pasaría a conformarse como una institución de enseñanza impartida en los espacios laborales. ${ }^{19}$ Para los intelectuales de $C y R$ estos cambios garantizaban que el conocimiento científico y técnico dejara de ser patrimonio de una minoría burguesa. No obstante, advertían que faltaba en Cuba la universalización de la educación, esto es, que la sociedad entera pudiera acceder a la universidad sin importar la procedencia económica y social. En consonancia con este anhelo, comprobamos que $C y R$ denunció abiertamente al gobierno militar argentino, a cargo del Gral. Onganía, por el cierre de centros de alfabetización de adultos donde centenas de obreros tomaban cursos a la par de sus actividades laborales.

Las desigualdades de clase entre los sectores medios y altos de la burguesía que realizaban estudios universitarios y los sectores populares que apenas accedían a ellos, fueron debatidas en términos de "concientización". Para los católicos radicalizados de $C y R$, el movimiento estudiantil podía cumplir un papel protagónico en la lucha de clases que atravesaba el mundo entero, colocándose de un lado u otro de los intereses en juego. En tal sentido, encontramos un artículo del Movimiento Estudiantil Ateneísta de Santa Fe que daba cuenta de las contradicciones de clase al interior de la Universidad del Litoral y, advertía que sus miembros no representaban a todos los sectores sociales ni el estudiantado se constituía como una clase social determinada, es decir, como una clase con intereses propios basados en una necesidad histórica común. Situación que podemos leer desde la óptica de los Ateneístas y de $C y R$ como una "ventaja" para los estudiantes que, al no tener intereses particulares, podían insertarse en los procesos revolucionarios luchando con los "oprimidos" en contra de los "opresores" $\left(C y R \mathrm{~N}^{\circ} 14\right.$, 1969, p. 30).

Hallamos aquí otro punto clave para pensar el papel del movimiento estudiantil: los jóvenes podían tomar consciencia de su condición como sector social, contemplando no sólo su

de vida, las características de las viviendas y servicios a los que accedían, la estructura urbana, datos sobre la educación, servicios públicos y migraciones. También cuestiones como la tenencia de la tierra, la distribución de partidas presupuestarias y la diversificación de la producción.

${ }^{19}$ Experiencias de estudiantes de Biología, de Química, de Arquitectura, de Hidráulica, de Economía y de Ingeniería que en 1969 se encontraban desarrollando el plan de café al sur de La Habana o con los campesinos en la misma zafra. 
posición como estudiante sino también proyectando su futura inserción profesional en el aparato de producción junto a obreros y campesinos. Intuimos que esto permitiría -para el grupo editor de la revista- superar el reformismo de 1918 y extender las aspiraciones revolucionarias, donde el estudiantado enmarcara sus propuestas en una perspectiva total y no inmediatista dentro del panorama general de la lucha de clases, combatiendo por los intereses históricos de los sectores marginados sin reducir sus acciones y reivindicaciones a los recintos universitarios. La estrategia de los intelectuales de $C y R$ era clara: mostrar un corte abrupto entre el pasado y el presente, una ruptura entre la generación que dio nacimiento al Manifiesto Liminar y la generación hija de la Revolución Cubana, entre quienes hicieron reforma y quienes ensayaban la revolución.

En la efervescencia del agitado año 69' la revista continuó modelando esta diferenciación entre los jóvenes reformistas del 18' y los revolucionarios de los 60'. Ubicamos múltiples notas que destacan la creciente participación del estudiantado argentino en las movilizaciones obreras y el avance de reivindicaciones que superaban lo meramente estudiantil. Descubrimos en el $\mathrm{N}^{\mathrm{o}} 15$ otro escrito de la Agrupación de Estudios Sociales de Córdoba llamado "Iglesia y Educación Liberadora". El texto retomaba la bandera del Documento de Medellín donde se proclamó la idea de educación liberadora, caracterizada por atender las necesidades culturales desde una perspectiva humanista y cristiana. La enseñanza tenía como fin "dignificar al ser humano" $(C y R$ $\mathrm{N}^{\circ} 15,1969$, p. 11). ${ }^{20}$

A pesar de lo novedoso de este enfoque, la agrupación admitía que la educación impartida por la Iglesia constituía todavía el privilegio de unos pocos mientras mantenía al "pueblo" alejado de las fuentes de cultura. Al reproducir este escrito, los intelectuales de $C y R$ señalaban que no era necesario luchar por una educación reformista como la que sostuvo el movimiento de 1918, puesto que, primero debían romperse las cadenas que ataban a los sectores populares a la tiranía del imperialismo. Sólo la transformación social, iniciada por la vía revolucionaria, permitiría alcanzar una verdadera educación liberadora que fuera más allá de simples reformas y permitiera a los hombres ser sujetos de su propio desarrollo.

En el número siguiente percibimos que la cuestión estudiantil adquirió centralidad como en ningún otro ejemplar. En el $\mathrm{N}^{\circ} 17$ la revista incluyó más de cinco notas: recopilamos escritos que van desde un manifiesto estudiantil, una crónica sobre la represión policial que sufrieron los estudiantes en el interior del país, un informe especial sobre las universidades latinoamericanas, una nota sobre rebeliones obrero-estudiantiles y la reedición del mensaje del sacerdote Camilo Torres, que ya había sido publicado en el $\mathrm{N}^{\circ} 2 / 3$ como analizamos más arriba.

El manifiesto firmado por la Federación Integralista Unión Nacional de los Estudiantes de Corrientes, resaltaba la superación del individualismo que permitió ir más allá de la exclusividad de las reivindicaciones universitarias y proclamaba la inminente liberación nacional y social del "pueblo". En simultaneo, advertimos que subrayaba la organización del estudiantado de la Universidad Nacional del Nordeste, quienes impulsaron huelgas para protestar en contra, por un lado, de la privatización de los comedores universitarios $\mathrm{y}$, por otro, del intento de implementación del plan educativo de la Agencia para el Desarrollo Internacional de Estados

\footnotetext{
${ }^{20}$ En 1968 se celebró la II Conferencia General del Episcopado Latinoamericano. Allí se resaltó el papel de la juventud en los procesos de transformación y la necesidad de atender al rechazo que hacían de las instituciones. Se presentó como reto la incorporación de ideas que congregaran a los jóvenes con iniciativas para hacer de la Iglesia un espacio de creatividad e innovación. La sanción del Documento de Medellín se convirtió en un hito decisivo en la configuración de la identidad de una "Iglesia latinoamericana" como una Iglesia libre del poder, próxima y compañera del "pueblo" en su camino de liberación.
} 
Unidos, inspirado en el modelo norteamericano Atcon. ${ }^{21}$ Entre las medidas promovidas por este plan, rechazaban aquellas orientadas a la departamentalización para reducir el plantel docente y directivo y, las que apuntaban a transformar la enseñanza en una empresa privada "productora de técnicos al servicio de los monopolios extranjeros" ( $C y R \mathrm{~N}^{\circ} 17,1969$, p. 5).

Frente a la posible implementación realizaban un llamado a las regionales del país para constituir coordinadoras de lucha con los demás agrupamientos populares, a efectos de fortalecer la unidad obrero-estudiantil en defensa de la educación. Como forma de reforzar la denuncia contra este plan, descubrimos que el equipo editor de $C y R$ anexa, en el mismo ejemplar, un informe especial titulado "Universidades latinoamericanas. La penetración yanqui y la rebelión estudiantil". Allí sostenían que la propuesta impulsaba falsamente el mejoramiento de la educación encubriendo un propósito central: el control de las universidades argentinas. ${ }^{22}$ Para los intelectuales de la revista, el gobierno norteamericano tenía como objetivo intervenir las casas de estudio, puesto que, eran instituciones compuestas por una paradoja: inicialmente fueron creadas para la élite, pero con el tiempo emergió en ellas un pensamiento radical por la influencia de las ideas marxistas. Como símbolo de esa paradoja y de la superación de la extracción clasista $C y R$ recalcó nuevamente la figura del "Che" Guevara.

En consonancia con el manifiesto, identificamos en las páginas siguientes una crónica sobre el estallido social en las provincias argentinas y la respuesta policial ante las revueltas estudiantiles que se propagaban en Resistencia, Rosario, Córdoba y Corrientes. La crónica detallaba el accionar de los estudiantes organizados en barricadas y corridas, la toma de algunos barrios con la ayuda de vecinos y obreros y, denunciaba la represión que culminó con heridos y muertos. Los estudiantes estaban disconformes con el aumento de los aranceles de los comedores universitarios decretado por el gobierno de facto. En una de las movilizaciones, el 15 de mayo de 1969, en Corrientes, fue asesinado Juan José Cabral estudiante de la Facultad de Medicina. A raíz de este hecho se extendieron nuevas protestas en las principales ciudades universitarias. Días más tarde, protagonizaron la rebelión conocida como el "Cordobazo". En homenaje al estudiante asesinado $C y R$ publicó, en la contratapa, una foto a color bajo el epígrafe "Dio su vida por una nueva juventud":

\footnotetext{
${ }^{21}$ Durante los años sesenta y setenta, el modelo inspirado en Rudolph Atcon (asesor del gobierno norteamericano para América Latina de la Organización de los Estados Americanos y de la Organización de Naciones Unidas) fue auspiciado por empréstitos del Banco Interamericano de Desarrollo. Consistió en una reforma de la educación superior que incluía la privatización, el cobro elevado de matrículas, el achicamiento de aportes estatales en políticas educativas y la reducción de los años de estudio para obtener mano de obra por medio de carreras "cortas". Promovía currículas individualizantes con conocimiento fragmentado y una desvalorización de las carreras de Ciencias Sociales frente a las tecnocráticas y pragmáticas.

${ }^{22} \mathrm{La}$ ayuda económica extranjera emprendió arduos debates en el seno universitario, fundamentalmente durante la gestión de Frondizi. Los aportes de Estados Unidos hicieron estallar la oposición de militantes estudiantiles, miembros de los cuadros medios de la universidad y de intelectuales de izquierda quienes entendían que "el dinero americano acarrearía, a mediano o largo plazo, la sumisión de la ciencia, la tecnología y la enseñanza superior" (Sigal, 1991, p. 93).
} 
María Josefina Lamaisón

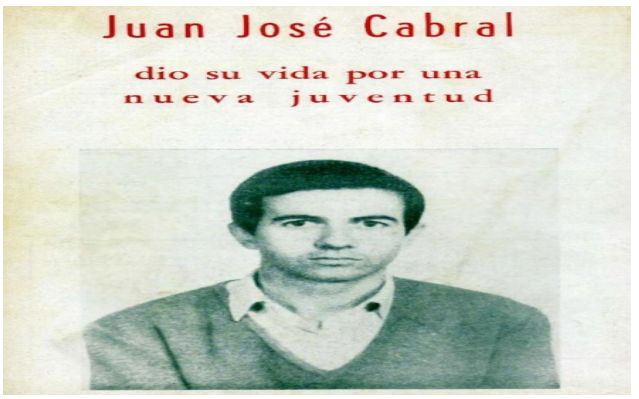

Ilustración 2. $C y R \mathrm{~N}^{\circ} 17$, junio 1969, p. 50.

Enfatizamos que los homenajes a guerrilleros, estudiantes y trabajadores asesinados fueron un recurso utilizado de forma reiterada por el grupo editor. La muerte de diversos militantes fue interpretada por $C y R$ en términos de heroicidad y de entrega a una "militancia consagrada a la causa colectiva" (Slipak, 2015, p. 39). Este tipo de reivindicaciones sobre aquellos que perdían la vida por la causa colectiva también la registramos en el número inicial de la revista. A través del epígrafe "Tenemos un corazón como un gigantesco fusil apuntando hacia la muerte" los titulares de tapa anticipaban un memorial del obrero-estudiante Santiago Pampillón. ${ }^{23}$ Asimismo, cuando fue asesinado el periodista Emilio Mariano Jáuregui el $\mathrm{N}^{\circ} 18$ publicó una carta del Centro de Estudios Camilo Torres que resaltaba como ejemplo y motivo de reflexión la vida de este intelectual revolucionario. ${ }^{24}$ Quienes murieron en manos represivas como Cabral, Pampillón y Jáuregui fueron asociados a la imagen de "mártires" -figuras vinculadas a la extensa historia del cristianismo- convertidos en símbolos de sacrificio y heroísmo.

Volviendo a la edición del $\mathrm{N}^{\circ} 17$, precisamos que concluye con una nota titulada " $\mathrm{La}$ Rebelión Estudiantil" donde se remarcó nuevamente la participación del estudiantado en los acontecimientos que hacían estallar las viejas estructuras de la sociedad. A continuación, en la misma página, notamos la transcripción del mensaje de Camilo Torres dedicado a los estudiantes -publicado en el $\mathrm{N}^{\circ} 2 / 3$ - que analizamos más arriba. La decisión de recuperar el mensaje por parte del agrupamiento intelectual de $C y R$, podemos comprenderla como un mecanismo de celebración del protagonismo estudiantil en la fase agitacional y como un llamado a los lectores de la revista a continuar con este tipo de acciones:

\footnotetext{
${ }^{23}$ Pampillón fue asesinado días previos al lanzamiento de $C y R$. Oriundo de la provincia de Mendoza, era estudiante de ingeniería aeronáutica en la Universidad Nacional de Córdoba y obrero mecánico en la empresa automotriz IKA-Renault. El 7 de septiembre de 1966, mientras participaba de una gigantesca asamblea convocada por la Federación Universitaria de Córdoba, donde se evaluaba una propuesta de lucha frente a la intervención del gobierno militar de Onganía, muere de tres disparos cuando las fuerzas policiales irrumpieron la asamblea. La noche de su asesinato los estudiantes fueron nuevamente reprimidos al concentrarse en el hospital donde habían trasladado el cuerpo del joven de 24 años.

${ }^{24} \mathrm{La}$ carta fue firmada por Nuncio Aversa director del Centro y algunos profesores como Jorge Gil Solá, Eduardo Jorge y Oscar Terán $\left(C y R \mathrm{~N}^{\circ} 18,1969\right.$ : 15). Jáuregui fue asesinado a los 29 años por la Policía Federal, cuando participaba el 27 de junio de 1969 en una manifestación en repudio a la llegada de Nelson Rockefeller al país. Militó en Vanguardia Comunista, fue parte del Sindicato de Prensa de Buenos Aires y secretario general de la Federación Argentina de Trabajadores de Prensa.
} 
María Josefina Lamaisón

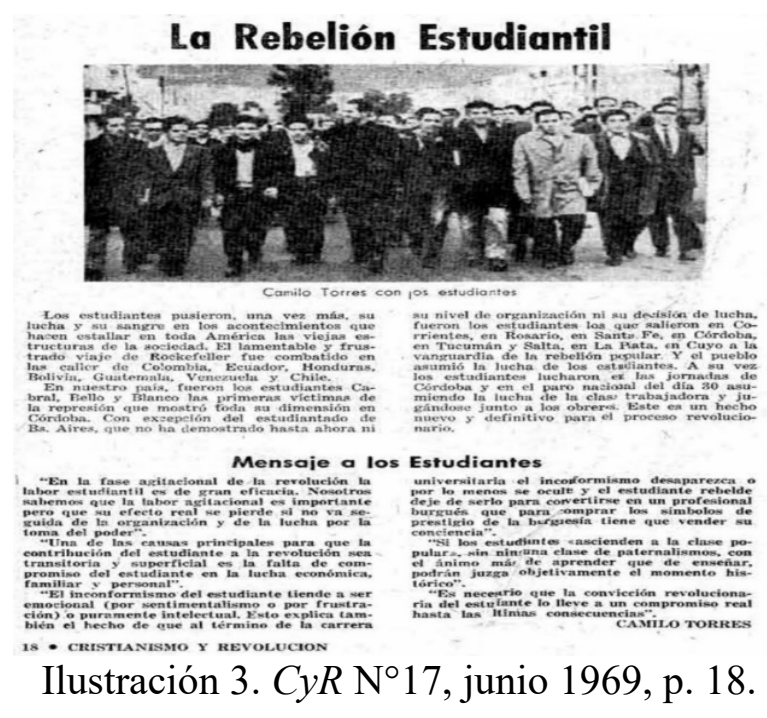

Pasado menos de un mes, $C y R$ lanzó el siguiente número que contenía un informe especial sobre el Cordobazo. ${ }^{25}$ Informe que describió los antecedentes de la lucha obreroestudiantil en contra de la política gubernamental, recalcando la oposición de la C.G.T. local y del movimiento estudiantil nucleado en la Federación Universitaria de Córdoba y en parte del integralismo. El grupo editor festejaba la convergencia opositora frente al imperante malestar que culminó con una verdadera rebelión popular:

Luego de numerosas escaramuzas, cabildeos, clausuras de la universidad, paros parciales y movilizaciones estudiantiles, el estudiantado participó en la calle junto a los obreros en las batallas que a diario se realizaban con las fuerzas de la represión y, al igual que los obreros, fueron apaleados, baleados y encarcelados. $\left(C y R, \mathrm{~N}^{\circ} 18, \mathrm{p} .7\right)$

Al acentuar estas palabras podemos inducir que, los redactores de la revista buscaban mostrar a sus lectores la llegada del anhelado "compromiso" de los intelectuales con la revolución social. Celebraban la unidad con el "pueblo" y el accionar de los estudiantes de la Universidad Católica, que, con parecidos fundamentos a los de las universidades laicas -aunque con diversos métodos- se sumaban cada vez más a la protesta general.

El fervor contestatario aumentó la represión policial y provocó las detenciones de cientos de intelectuales, obreros y estudiantes. Ante el contexto de mayor censura advertimos un "giro" en los debates de la revista: disminuyeron casi por completo aquellos escritos que detallaban las protestas obrero-estudiantiles, mientras que, proliferaron las publicaciones sobre las situaciones de hostilidad. Se sumaron tres nuevos apartados - Solidaridad, Los Nuestros y Presos Políticosque enumeraban nóminas con los nombres y apellidos de los encarcelados por cuestiones políticas y reproducían pronunciamientos de distintos agrupamientos frente a las crecientes persecuciones. $^{26}$

${ }^{25}$ Cabe señalar que $C y R$ rivalizó con la revista Los Libros respecto a cómo interpretaban los sucesos de Córdoba y los caminos que debía seguir la lucha insurreccional (Celentano, 2014).

${ }^{26}$ En el apartado Presos Políticos encontramos una carta de la Federación Universitaria de Buenos Aires destinada a los estudiantes y a la opinión pública. La misma denunciaba la cantidad de presos políticos, la clausura de diarios y 
Incluso, como adelantamos, en agosto de 1969 el propio director de la revista sería encarcelado. Como respuesta, el Centro de Estudios Camilo Torres redactó una declaración que repudiaba la intimidación que sufrían los cristianos radicalizados y convocaba a los lectores a movilizarse por la libertad de García Elorrio y la de todos los presos políticos. También registramos un comunicado sobre persecuciones en la Universidad Católica de Córdoba, que denunciaba la suspensión arbitraria de estudiantes por orden del Rector Dr. Storni, entre estos, Miguel Ángel Bustos, María Leonor Pappaterra, Roberto Calabrese, Claudio Ehrenfeld y Ernesto Castro. $C y R$ afirmaba que con tal actitud la universidad cordobesa negaba los principios del Documento de Medellín "demostrando que continuaba atada al statu quo y a los intereses económicos de quienes la dirigían" (CyR $\mathrm{N}^{\circ} \mathrm{N}^{\circ} 20,1969$, p. 7). ${ }^{27}$

Nos interesa puntualizar que, los textos de las diversas declaraciones, cartas y comunicados de denuncias eran generalmente antecedidos por enunciados que explicitaban los destinatarios de las mismas. En reiteradas oportunidades se dirigieron a "los estudiantes", a "los cristianos", al "mundo obrero" y a "la opinión pública". Esto nos permite hipotetizar que además de informar y dar a conocer la situación represiva, el agrupamiento de $C y R$ continuaba apostando a la unidad obrero-estudiantil como modo de resistencia ante el avance de la violencia militar. Los llamamientos a enlazar fuerzas se multiplicaron a inicios del año 1970.

En enero de ese año $C y R$ lanzó el último número bajo la dirección de García Elorrio, quien muere en un dudoso accidente de tránsito unos meses después de quedar en libertad. La revista editó en ese ejemplar el manifiesto "Hacia el Congreso Nacional de Unidad. La crisis del movimiento estudiantil" de la Federación Universitaria Argentina (FUA). Allí, los estudiantes universitarios afirmaban que había llegado la hora de la unidad combativa con la clase obrera tras las banderas de la liberación nacional y social, reconociendo un único camino: "hacer de todo el país, un Córdoba triunfante" $\left(C y R \mathrm{~N}^{\circ} 22,1970\right.$, p. 22). Asimismo, se prescribió que el estudiantado debía ser protagonista frente a la reacción conservadora: "que cada curso sea una trinchera, que cada estudiante sea un portavoz y portaestandarte de nuestras banderas de combate" (CyR $\mathrm{N}^{\circ} 22,1970$, p. 24). Los agremiados a la FUA rechazaban el participacionismo vertical, acusaban la existencia de un "falso diálogo" entre los claustros y exigían un gobierno estudiantil-docente igualitario resuelto por asamblea. Los tiempos radicalizados pusieron en primer plano a los cuerpos de delegados y las asambleas estudiantiles como canales privilegiados de la participación política. Las visiones reformistas que hacían hincapié únicamente en los problemas de la universidad ganaron desprestigio. Frente a la autonomía universitaria tradicional, los estudiantes radicalizados de la FUA bosquejaron una independencia absoluta de los formalismos institucionales y académicos, ningún "paliativo reformista" podía transformar la universidad, puesto que, la verdadera democratización recién llegaría con la liberación nacional y social (Dip, 2016).

A partir del $\mathrm{N}^{\circ} 23$, Casiana Ahumada asumió la dirección de la revista. La asunción conllevó cambios en la materialidad y en los contenidos temáticos. La cuestión estudiantil perdió espacio entre las páginas que giraron, casi con exclusividad, a los debates sobre la lucha armada como vía revolucionaria. Pasarían cuatro números desde el manifiesto de la FUA hasta la última

revistas, la recurrente intervención de las universidades desde 1966 y, la progresiva aristocratización y degradación científico-cultural.

${ }^{27}$ El comunicado fue firmado por $C y R$, el Movimiento de Cristianos del Tercer Mundo, el Centro de Estudios Parroquia del Carmen, el Centro de Estudios Populares Hilda Guerrero, el Centro de Estudios Camilo Torres, la Agrupación de Estudios Sociales, el Centro de Estudios Juan XXIII y el Movimiento 15 de mayo de la Universidad Católica de Santa Fe. 
María Josefina Lamaisón

publicación que registramos sobre la universidad. En el №26, encontramos una nota fechada el 1 de septiembre de 1970, firmada por personal docente de las Cátedras Nacionales de Sociología que cristalizaba el clima de extrema censura que vivenciaban los universitarios, fundamentalmente aquellos afines al peronismo de izquierda. Dichas cátedras fueron críticas de las teorías sociológicas vigentes e intentaron vincular la enseñanza al proceso social de Argentina. ${ }^{28} \mathrm{La}$ carta denunciaba las agresiones arbitrarias que sufrían los docentes, por parte de las autoridades facultativas, producto de reconocerse públicamente como "peronistas" que combatían a las clases dominantes, en su intento de imponer una perspectiva técnico-empresarial en los circuitos académicos.

Finalmente, la censura alcanzó a los intelectuales que editaban la revista. Los militares confiscaron en diciembre de 1971 el último número de $C y R$ y encarcelaron a su directora, que dos años después saldría del país. Las fuerzas represivas pusieron fin al proyecto editorial y muchos de sus integrantes emprendieron un largo camino hacía el exilio.

\section{Consideraciones finales}

En las páginas que componen este artículo, presentamos cómo el agrupamiento intelectual que editó la revista $C y R$ intervino en la época de los sesenta modelando posicionamientos sobre diversos tópicos en la coyuntura política y social, caracterizada por un aumento de la conflictividad social producto de la oposición a la dictadura militar, de los cambios internos atravesados por los sectores de izquierda y la complejización del mundo católico desde el accionar de los movimientos tercermundistas. Como señalamos, otras investigaciones abordaron este órgano de prensa priorizando en su análisis el eje que relaciona violencia armada, política y religión (Lenci, 2003; Slipak 2015; Campos, 2016). El énfasis sobre la violencia revolucionaria permitió reconstruir los lazos que los intelectuales de la revista tuvieron con otras agrupaciones afines a la lucha armada. Sin embargo, esta lectura oscureció otros puntos posibles de indagación como las redes constituidas con las organizaciones estudiantiles de universidades católicas y laicas.

Siguiendo este eje de interpelación -desde los aportes de la historia intelectual y su "giro material"- nos preguntamos qué discursos sobre los estudiantes y la universidad aparecieron en los escritos de $C y R$, qué figuras emergieron en los debates sobre la cuestión nacional, la liberación y la universidad y, cómo apareció el legado de la Reforma de 1918. Desde estos interrogantes pudimos iluminar que las publicaciones de la revista se orientaron a destacar la participación del movimiento estudiantil, fundamentalmente la vertiente católica, en los cambios revolucionarios que se produjeron en América Latina fijando una agenda cultural que se proclamaba a favor de la unidad obrero-estudiantil. Registramos que la revista asignaba a los estudiantes universitarios el rol programático de "sujetos conscientizadores" que, junto al "pueblo" y la clase trabajadora, lucharían por transformar el sistema imperialista buscando la liberación nacional y social de los oprimidos del Tercer Mundo.

${ }^{28}$ Entre 1968 y 1974 la sociología argentina se encontraba fragmentada: la "nacional" batallaba contra una "marxista", mientras que, los herederos de la sociología "científica" permanecían en centros de investigación privados y articulados a las redes de la comunidad internacional (Sigal, 1991, p. 32). Durante los años sesenta aparecieron agrupaciones de estudiantes y profesores que se reconocían abiertamente peronistas. En este marco, se crea en la UBA, las Cátedras Nacionales de Sociología. 
Los intelectuales de $C y R$ cuestionaron el carácter cientificista de la universidad y el alejamiento de las necesidades históricas de los sectores populares. Celebraron el protagonismo de los estudiantes radicalizados que buscaron transformarla y ponerla al servicio de la sociedad entera. Sin embargo, adherían a la idea de que estas transformaciones llegarían solamente luego del cambio radical de las estructuras sociales. En este aspecto, enfatizamos que fueron críticos de los postulados de la Reforma de 1918. Si bien coincidían con algunos derechos conquistados por los estudiantes reformistas como la libertad de cátedra, el co-gobierno, la autonomía, la importancia de la investigación y la extensión como formas de acercarse a los sectores "marginados", entendían que eran simplemente "reformas", reivindicaciones exclusivamente estudiantiles que no trastocarían los verdaderos cimientos de la universidad necesarios para alcanzar la universalización de los estudios superiores. Antes que el reformismo era ineludible transformar primero el sistema a través de la revolución.

Este espíritu transformador hace eco de la radicalización política asumida por los católicos de $C y R$, que inscribimos bajo el modelo del intelectual revolucionario consagrado en la II Declaración de La Habana. Desde esta posición reforzaron las críticas a las instituciones académicas, promovieron el rescate de figuras de estudiantes universitarios que dejaban sus intereses de clases y se introducían en las experiencias guerrilleras -como Antonio Mella y Ernesto Guevara- y, se pronunciaron a favor de lo que entendían como el modelo de "educación liberadora", definido en el Documento de Medellín. En consonancia, reivindicaron el socialismo cubano y se manifestaron como opositores del intervencionismo norteamericano en las universidades latinoamericanas. Denunciaron las fuentes de financiamiento provenientes de Estados Unidos, que, a los ojos de la revista, tenía como objetivo transformar la educación en un sistema privado a disposición de los intereses de los monopolios de las clases dominantes.

Por otra parte, identificamos que las figuras sobre el movimiento estudiantil estuvieron inicialmente referenciadas en los agrupamientos de Colombia y Cuba, desplazándose en los sucesivos ejemplares, hacia el protagonismo del estudiantado argentino en las rebeliones populares, especialmente los estudiantes católicos, que habían protagonizado revueltas como el Cordobazo, pero también agitaciones en Rosario, Santa Fe y Mendoza.

Finalmente, notamos un cambio o "vuelco" en los dilemas abordados por la revista hacia fines de 1969 e inicios de 1970. Los ejemplares incorporaron nuevos apartados que se dedicaron casi con exclusividad a denunciar las persecuciones y censuras por parte de las fuerzas represivas sobre los católicos radicalizados. Los últimos esfuerzos del colectivo intelectual de $C y R$ se orientaron entonces a reforzar, más que nunca, la unidad obrero-estudiantil.

\section{Bibliografía}

Altamirano, Carlos (2001). Bajo el signo de las masas (1943-1973). Buenos Aires: Ariel. . (2011). Peronismo y cultura de izquierda. Buenos Aires: Siglo Veintiuno Editores. . (2013). Intelectuales. Notas de investigación sobre una tribu inquieta. Buenos Aires: Siglo Veintiuno Editores.

Barletta, Ana y Tortti, María Cristina (2002). "Desperonización y peronización en la universidad en los comienzos de la partidización de la vida universitaria" en: Krotsch, P. (Ed.), La universidad cautiva. La Plata: Ed. Al Margen. 
María Josefina Lamaisón

Beigel, F. (2003). "Las revistas culturales como documentos de la historia latinoamericana". Utopías y Praxis Latinoamericana, vol.8, $\mathrm{N}^{\circ} 20$, Venezuela.

Bozza, Juan Alberto (2014). "La resignificación revolucionaria del peronismo y sus protagonistas durante la etapa de la proscripción" en: Tortti, M. C., Chama, M. y Celentano, A. (Dir.), La nueva izquierda argentina (1955-1976). Socialismo, peronismo y revolución. Prohistoria.

Buchbinder, Pablo (2005). Historia de las universidades argentinas. Buenos Aires: Sudamericana. Bustelo, Natalia (2018). Todo lo que necesitás saber sobre la Reforma Universitaria. Buenos Aires: Paidós.

Campos, Esteban (2016). Cristianismo y Revolución. El origen de montoneros. Violencia, política y religión en los 60. Ciudad Autónoma de Buenos Aires: Edhasa.

Celentano, Adrián (2014). "Insurrección obrera y compromiso intelectual. Los Libros y Cristianismo y Revolución frente al Cordobazo y el Viborazo" en: Archivos, ํ4, pp.53-75.

Chartier, Roger (1996). Escribir las prácticas. Foucault, de Certeau, Marin. Buenos Aires, Manantial.

Devés Valdéz, Eduardo. (2007). Redes intelectuales en América Latina. Hacia la constitución de una comunidad intelectual. Chile: Colección Idea.

Dip, Nicolás (2016). "Libros y alpargatas. Las tramas discursivas y organizativas del proceso de peronización de estudiantes, docentes e intelectuales de la Universidad de Buenos Aires. 1966-1974”. Tesis de posgrado. Universidad Nacional de La Plata. Facultad de Humanidades y Ciencias de la Educación: Memoria Académica.

Gilman, Claudia (2003). Entre la piedra y el fusil. Debates y dilemas del escritor revolucionario en América Latina. Buenos Aires: Siglo Veintiuno Editores.

Gordillo, Mónica (2003). "Protesta, rebelión y movilización: de la resistencia a la lucha armada (1955-1973)" en: James, D. (e), Nueva Historia Argentina, tomo IX. Buenos Aires: Sudamericana.

Lenci, Laura (2003). "Cristianismo y Revolución (1966-1971). Una primera mirada". Buenos Aires: CEDINCI.

Pita González, Alexandra (2014). "Las revistas culturales como soportes materiales, prácticas sociales y espacios de sociabilidad" en: Hanno Ehrlicher, Nanette Rißler-Pipka (eds.), Almacenes de un tiempo en fuga: Revistas culturales en la modernidad Hispánica. Alemania: Shaker Verlag.

Sarlo, Beatriz. (1992). "Intelectuales y revistas: razones de una práctica". América: Cahiers du CRICCAL, $\mathrm{N}^{\circ} 9-10$.

Sigal, Silvia. (1991). Intelectuales y poder en la década del sesenta. Buenos Aires: Puntosur.

Slipak, Daniela (2015). Las revistas montoneras: cómo la organización construyó su identidad a través de sus publicaciones. Buenos Aires: Siglo Veintiuno Editores.

Tarcus, Horacio (2007). Marx en la Argentina. Sus primeros lectores obreros, intelectuales y científicos. Buenos Aires: Siglo Veintiuno Editores. . (2020). Las revistas culturales latinoamericanas. Giro material, tramas intelectuales y redes revisteriles. Temperley: Tren en Movimiento.

Terán, Oscar (2013). Nuestros años sesentas. La formación de la nueva izquierda intelectual argentina, 1956-1966. Buenos Aires, Siglo Veintiuno Editores. 
María Josefina Lamaisón

Tortti, María Cristina (2005). "La Nueva Izquierda en la historia reciente de la Argentina" en: Cuestiones de Sociología. Revista de Estudios Sociales No 3, Departamento Sociología, FaHCE-UNLP. La Plata: Prometeo.

Touris, Claudia (2007). Sociabilidad e identidad político-religiosa de los grupos católicos tercermundistas en la argentina (1966-1976). I Jornadas Nacionales de Historia Social, 30, 31 de mayo y 1 de junio de 2007, La Falda, Córdoba.

Documentos de la revista Cristianismo y Revolución analizados

“Mensaje a los estudiantes" de Camilo Torres. CyR, N²/3, oct-nov 1966, p. 19.

"La protesta en boca de los fusiles" de Eduardo Galeano. CyR, N6/7, abril 1968, pp. 22-26.

“Colombia: declaración del MUAP”. CyR, №6/7, abril 1968, pp. 36-37.

"Cuba: ofensiva revolucionaria. A 15 años del 26 de julio". CyR, $N^{\circ} 9$, septiembre 1968, pp. 3944.

"Tucumán: informe de la Agrupación de Estudios Sociales de Córdoba". CyR, Nº10, octubre 1968, pp. 8-12.

"Fidel Castro explica la revolución universitaria". CyR, N¹3, abril 1969, pp. 30-40.

"Movimiento Ateneista de Santa Fe. Hacia una perspectiva revolucionaria". CyR, $\mathrm{N}^{\circ} 14$, abril 1969, pp. 28-32.

"Iglesia y educación liberadora". CyR, №15, mayo 1969, p.11.

"Los integralistas junto al pueblo". CyR, $\mathrm{N}^{\circ} 17$, junio 1969, p.5.

"Crónica argentina". CyR, №17, junio 1969, pp. 6-9.

"Universidades latinoamericanas. La penetración yanki y la rebelión estudiantil". CyR, N¹7, junio 1969, pp. 14-17.

"La rebelión estudiantil” y “Mensaje a los estudiantes de Camilo Torres”. CyR, $\mathrm{N}^{\circ} 17$, junio 1969, p. 18.

"El Cordobazo". CyR, №18, julio 1969, pp.6-8.

"Emilio M. Jauregui. Centro de Estudios Camilo Torres". CyR, №18, julio 1969, pp.14-15.

"Centro de Estudios Camilo Torres". CyR, N¹9, agosto 1969, p.4.

"Solidaridad". CyR, N²0, sep-oct 1969, p.1

"FUGBA: a los universitarios y a la opinión pública". CyR, №20, sep-oct 1969, pp.6-7.

"Hacia el Congreso nacional de unidad. La crisis del movimiento estudiantil. Llamamiento de la FUA”. CyR, N²2, enero 1970, pp.21-26.

"Los docentes de las Cátedras Nacionales de Sociología ante el conflicto planteado por la intervención”. CyR, N²6, nov-dic 1970, pp.25-26. 